\title{
In vitro Antioxidant Potential of Fatty Acids Obtained by Direct Transmethylation from Fresh Cordia sebestena Flowers
}

\author{
Olubunmi Atolani, Oluwatimilehin O. Kayode, Oluwaseeni \\ Adeniyi and Charles B. Adeosun
}

Department of Chemical Sciences, Redeemer's University, P.M.B. 3005, Mowe, Nigeria.

\begin{abstract}
The determination of fatty acid profile of plant material is often attained via multistep procedures. Recent innovation has made it possible to obtain fatty acids from fresh matrix in a single step. This study was conducted to analyze the fatty acids present in $C$. sebestena using direct transmethylation in a one-step procedure with methanol:benzene: hexane:aluminium chloride:sulphuric acid (37:20:36:5:2 v/v) as transmethylation reagents and gas chromatography/mass spectrophotometry, GC-MS for quantification. The antioxidant potential of the transmethylation product was also evaluated using DPPH assay. GC-MS revealed the presence of seventeen fatty acids in $C$. sebestena. Palmitic acid $(32.45 \%)$, myristic acid $(21.49 \%)$, cis-oleic acid $(9.57 \%)$, 13-octadecenoic acid $(5.76 \%)$ and stearic acid $(4.95 \%)$ were the major fatty acids while gondoic acid $(0.88 \%)$ (an omega-9 fatty acid) and other 11 fatty acids $(0.11$ to $0.96 \%)$ constitute the minor components. Non-fatty acids compounds $(17.43 \%)$ were also present in the obtained product. Yield (3.33\% fresh weight) was modest and product had high antioxidant activity suggesting the viability of the method in determining the fatty acid profile of the plant. The procedure saves time and resources that are associated with conventional multistep method. Results obtained showed evidence that Cordia sebestena could be an attractive source of fatty acids that are important natural antioxidants.
\end{abstract}

Keywords: Antioxidant, Cordia sebestena, Essential fatty acid, FAMEs, GCMS, Transesterification,

Correspondence : O. Atolani Address: Department of Chemical Sciences, Redeemer's University, P.M.B. 3005, Mowe, Nigeria Tel:+2348034467135E-mail: tolanvent@yahoo.com;atolani@run.edu.ng DOI: $10.32945 /$ atr3626.2014 


\section{INTRODUCTION}

Flowers of plants are good sources of dyes and pigments (Doqan et al., 2003), flavonoids (Park et al., 2000; Ilić et al., 2004), glycosides (Tomczyk and Gudej, 2002a), fatty acids (Tomczyk and Gudej, 2002b), alkaloids (Hartmann and Zimmer, 1986; Biller et al., 1994), coumarins (Dudekmakuch and Matlawska, 2013; Martino et al., 2006; Pereira, 1997), polyphenolics (Gudej and Tomczyk, 1999) and carboxylic acids (Durust et al., 2001) of medicinal importance. For instance, the qualities of honey being used for medicinal purposes are usually determined by the type of flower the bees feed on. Honey produced by bees that feed heavily on flowers containing high concentration of toxic alkaloids could also be poisonous. Flowers have various phytochemicals which determine its pharmacological usefulness. The flowers of Inula britannica have been used for the treatment of digestive disorders, bronchitis, and inflammation in traditional medicine and the butanol extract has been shown to possess antioxidant activity in an in vitro analysis (Park et al., 2000). The flowers of Fagopyrum esculentum contain a conjugated photo-reactive quinine, fagopyrin (Hagels et al. 1995), which has been known to induce primary photosensitization in cattle, sheep, goats, and other animal species for many years (Sheard et al. 1928). Obviously, flowers of plants play a vital role in folkloric medicine. Chemical composition of volatiles from the leaf, flower, bark, seed and fruit of Cordia sebestena (family Boraginaceae) has been partly reported in previous studies (Adeosun and Sojinu, 2012; Agunbiade et al., 2013; Adeosun et al., 2013a, 2013b). In the present study, the fatty acid profile of the flower of C. sebestena (Figure 1 ) is determined using a one-step procedure and its in vitro antioxidant potential assayed.

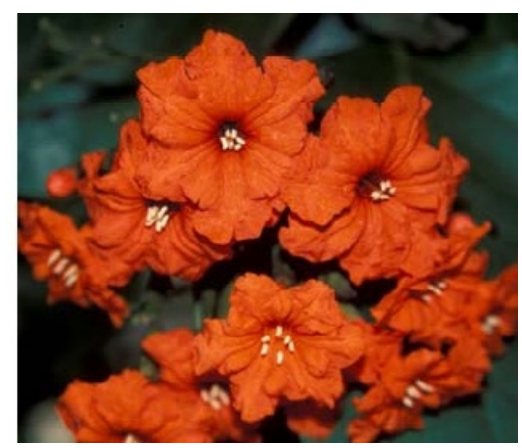

Figure 1: Cordia sebestena flower. 


\section{MATERIALS AND METHODS}

\section{Plant Material}

Flowers of $C$. sebestena were randomly collected from fruiting trees within the neighborhood of Redeemer's University, Ogun State, Nigeria. The plant was taxonomically identified by a botanist at the Herbarium of the Botany Department of the University of Lagos, Lagos, Nigeria where a voucher specimen, LUH 5551 had been previously deposited.

\section{Chemicals}

Solvents and chemicals which included hexane, benzene, methanol, sulphuric acid, sodium sulphate, 1,1-Diphenyl-2-picrylhydrazyl and tocopherol were of analytical grade. Where necessary, solvents were redistilled.

Preparation of sample using One-step Isolation and transmethylation of fatty acids:

The sample for fatty acid analysis was prepared using direct transmethylation method as described by Garces and Mancha (1993) with slight modification. The reaction was performed in one-necked glass reactor equipped with a reflux condenser. Fresh flower sample of $C$. sebestena $(15 \mathrm{~g})$ was added with $100 \mathrm{~mL}$ of methanol:benzene:hexane: aluminum chloride:sulfuric acid (37:20:36:5:2 v/v) solution, heated at 100C for $30 \mathrm{~min}$, then cooled and filtered. The organic components in the supernatant were separated in a separatory funnel and washed with distilled water several times and then concentrated. Yield of the transmethylated product was recorded. The transmethylated product was not pure FAMEs as it contained little non-fatty acid compounds as well.

\section{In vitro Antioxidant Assay}

The free radical scavenging activity of the transmethylated product from the flower of $C$. sebestena was evaluated in vitro using the 1,1Diphenyl-2-picrylhydrazyl (DPPH) assay. The spectrophotometric assay was carried out in duplicate according to the method previously reported (Atolani et al., 2012b). The DPPH free radical was freshly prepared at a 0.1 
mM concentration in methanol and protected from light. Stock solutions of the oil and standard (1 mg.mL $\mathrm{m}^{-1}$ each) were prepared and diluted with methanol to final concentrations of 1000, 500, 300, 200, 100, 50 and 5 $\mu \mathrm{g} . \mathrm{mL}^{-1}$. One (1) $\mathrm{mL}$ of DPPH $(0.1 \mathrm{mM})$ was added to solutions of the sample as well as the standard ( $\alpha$-tocopherol) and incubated for 30 minutes in the dark. The absorbances of the samples were read at $517 \mathrm{~nm}$. Blank experiment was also carried out to determine the absorbance of DPPH before interacting with the sample. The decreasing absorbance of the DPPH solution indicates an increase in DPPH radical scavenging activity. The activity was given as percent DPPH radical scavenging, and was calculated using the equation:

$$
\% A O C=\frac{\left[\mathrm{Abs}_{\text {control }^{-}} \mathrm{Abs}_{\text {sample }}\right]}{\mathrm{Abs}_{\text {control }}} \times 100
$$

Where: \%AOC means percentage antioxidant capacity, $\mathrm{Abs}_{\text {control }}$ is the absorbance of the control and $\mathrm{Abs}_{\text {sample }}$ is the absorbance of the sample at $517 \mathrm{~nm}$.

Results were expressed as mean values \pm standard deviations (SD). For comparison, one-way analysis of variance (ANOVA) was used with the GraphPAD software version 3.0. Significance limit was set at $\mathrm{P}<0.0001$.

\section{FAMEs Analysis}

The GC-MS analysis was carried out using Agilent Technology 7890A gas chromatograph GC-FID, equipped with a fused silica capillary column HP-5MS (30 m by $0.32 \mathrm{~m}, 0.5 \mu \mathrm{m}$ film thickness) on ultra-pure helium gas and coupled to a mass selective detector (mass spectrometer). The injector and interface were operated at 250 and $380{ }^{\circ} \mathrm{C}$, respectively. The oven temperature was raised from 60 to $270^{\circ} \mathrm{C}$ at a heating rate of $5^{\circ} \mathrm{C} \mathrm{min}^{-1}$ and then held isothermally at this temperature. The sample was injected in a splitless mode using 7683 series Agilent Technologies injector. The percentages of the compounds were obtained by GC-FID analysis.

Mass spectrometry (MS), qualitative analyses were carried out on a MS 5975, msd Agilent Technologies operated at an ionization voltage of $70 \mathrm{eV}$ over an acquisition mass range under the experimental conditions reported for GC-FID analysis. The chemical composition of the product obtained was identified based on its linear retention indices and 
on comparing their MS spectra with data obtained from the National Institute Standard and Technology (NIST, 2008) database. The relative proportion of the constituents was calculated from the GC peak areas based on the total ion chromatogram (TIC) and expressed as percentages.

\section{RESULTS AND DISCUSSION}

The direct methylation, also called one-step extraction, afforded the quick and easy extraction, detection and identification of fatty acids from the fresh plant material during GC-MS analysis. Obviously, the procedure saves time and resources by doing away with some steps in the conventional method which involves drying of plant material, pulverization, soxhlet extraction of lipid, acid/base hydrolysis, and esterification. In this method, extraction and transmethylation are combined into one step and therefore overcomes several limitations of the multistep methodology, giving rise to a simpler and faster analysis while consuming less organic solvent (Dickey et al, 2002; Indarti et al., 2005; Meier et al., 2006). This method releases the fatty acids from the matrix by breaking the ester bonds and thus making the extraction more efficient than that for recovering fatty acid in lipid that are tightly bound to the matrix (Xiao, 2010). It had been reported that direct methylation gave comparable fatty acid profile and higher fatty acid recovery of marine tissues than the conventional extraction followed by transesterification (Meier et al., 2006). The method which has been used successfully for fatty acid analysis in different plant materials (Lepage et al., 1986) is simple, cost efficient and environmentally sound requires small amount of sample and gives high recovery of total fatty acids. It further fulfills the U.S. Nutritional Labeling and Education Act (NLEA) demand (Xiao, 2010).

Fatty acids are important class of compounds present in varying quantity in almost all parts of medicinal plants (Atolani et al., 2011, 2012a; Fabiyi et al., 2012). The recipe used in this study contains hexane and benzene as extracting solvents, sulphuric acid for hydrolysis, aluminium chloride as catalyst, and methanol for methylation. The FAMEs were thus obtained in a single procedure with a yield of 3.33 of the total flower material.

GC-MS identified thirty-six compounds in C. sebestena flower; seventeen of which were fatty acids $(82.57 \%)$ while nineteen were nonfatty acid compounds (17.43\%). The major fatty acids include palmitic acid (32.45\%), myristic acid (21.49\%), cis-oleic acid (9.57\%), 13-octadecenoic 
In vitro Antioxidant Potential of Fatty Acids

acid (5.76\%), and stearic acid (4.95\%) as shown in Table 1. Gondoic acid: an omega-9 fatty acid, was detected in low amount (0.88\%). Palmitic acid, also known as cetylic acid, plays an important role in biological processes (Benoit et al., 2009). Furthermore, palmitic acid has been reported has been reported to cause growth inhibition and apoptosis induction in human gastric cancer cells (Oyugi et al., 2011). Oleic acid, an unsaturated fatty acid, was detected in a relatively low amount while myristic and palmitic acids were found as the major saturated fatty acids. The major non-fatty acid compounds detected (Table 2) include heptadecane (6.87\%), heneicosane (1.28\%), cyclopentadecanone $(0.92 \%), 6,10,14$ trimethyl-2-Pentadecanone $(0.9 \%)$, 5-tetradecene $(0.86 \%)$, and $2,3-$ dihydro-3,3,5,7-tetramethyl-1H-Inden-1-one (0.6\%). The non-fatty acid components (17.43\%) could have also contributed to the biological activity.

Table 1. GC-MS profile of fatty acids present in C. sebestena flower obtained by direct transmethylation method

\begin{tabular}{|c|c|c|c|}
\hline ĒOE & Name of Compounds & RT & \%Composition* \\
\hline 1 & Caprylic acid & 08.36 & 0.18 \\
\hline 2 & Methyl 8-oxooctanoic acid & 12.17 & 0.11 \\
\hline 3 & Caprynic acid & 13.27 & 0.36 \\
\hline 4 & Methyl 8-formyloctanoic acid & 13.86 & 0.96 \\
\hline 5 & $\begin{array}{l}\text { Methyl 10-methyl-undecanoic } \\
\text { acid }\end{array}$ & 15.18 & 0.41 \\
\hline 6 & Dodecanoic acid & 16.27 & 1.84 \\
\hline 7 & Myristic acid & 18.19 & 21.49 \\
\hline 8 & Pentadecanoic acid & 19.36 & 0.45 \\
\hline 9 & Palmitic acid & 20.81 & 32.45 \\
\hline 10 & 14-methylhexadecanoic acid & 21.84 & 0.44 \\
\hline 11 & cis-Oleic Acid & 22.77 & 9.57 \\
\hline 12 & Stearic acid & 23.05 & 4.95 \\
\hline 13 & 13-Octadecenoic acid & 23.52 & 5.76 \\
\hline 14 & $\alpha$-eleostearic acid & 24.4 & 0.46 \\
\hline 15 & 18-methylnonadecanoic acid & 25.17 & 1.26 \\
\hline 16 & Gondoic acid & 25.46 & 0.88 \\
\hline \multirow[t]{2}{*}{17} & Docosanoic acid & 27.17 & 1.00 \\
\hline & Total & & 82.57 \\
\hline
\end{tabular}

RT: Retention Time; *: \% composition on the basis of oil yield from fresh sample. 
Table 2. GC-MS profile of non-fatty acids present in C. sebestena flower obtained by direct transmethylation method.

\begin{tabular}{rlrr}
\hline S/N & Compounds & RT & \% Composition* \\
\hline 1 & 2-butoxy-Ethanol & 3.77 & 0.31 \\
2 & 2-hepthanal, (E)- & 4.82 & 0.42 \\
3 & 2-Pentyl Furan & 5.58 & 0.2 \\
4 & 2-Nonen-1-ol,(E) & 7.95 & 0.21 \\
5 & 2-Decenal, (Z)- & 10.93 & 0.52 \\
6 & 2-Nonanone & 11.5 & 0.37 \\
7 & 2,4-Decadienal, (E,E)- & 11.89 & 0.24 \\
8 & 2-Decenal, (E)- & 12.67 & 0.11 \\
9 & 5-Tetradecene, (E)- & 13.1 & 0.86 \\
10 & 5,6,7,7a-tetr ahydro-4,4,7a-trimethyl-2(4H)- & 15.3 & 0.45 \\
& Benzofuranone & & \\
11 & 2,3-dihydro-3,3,5, 7-tetramethyl-1H-Inden-1-one & 16.54 & 0.6 \\
12 & 2-n-Octylfuran & 16.65 & 0.37 \\
13 & 6,10,14-trimethyl-2-Pentadecanone & 19.62 & 0.9 \\
14 & (R)-(-)-14-Methyl-8-hexadecyn-1-ol & 23.2 & 0.49 \\
15 & 1-chloro-Octadecane & 23.77 & 1.77 \\
16 & Heptadecane & 24.91 & 6.87 \\
17 & Cyclopentadecanone & 24.97 & 0.92 \\
18 & Octadecane & 25.85 & 0.54 \\
19 & Heneicosane & 29.31 & 1.28 \\
& Total & & 17.43 \\
\hline
\end{tabular}

RT: Retention Time; *: \% composition on the basis of oil yield from fresh sample.

\section{Free Radical Scavenging Activities}

The in vitro antioxidant activity of the fatty acid methyl esters obtained by direct transmethylation from $C$. sebestena flower was evaluated. Although, it was observed to be less potent than $\alpha$-tocopherol (figure 2), the activity was however significantly different (ANOVA, $p<0.0001$ ) and dose responsive. The percent antioxidant capacity increases as concentration of the sample and standard increases and ranges between 32 to 62 and 75 to $92 \%$ for the C. sebestena FAMEs and $\alpha$-tocopherol, respectively (Fig. 2). The ability of the FAMEs to scavenge the DPPH radical is an indication that the plant may be useful in slowing down the progress of oxidative stress. 
In vitro Antioxidant Potential of Fatty Acids

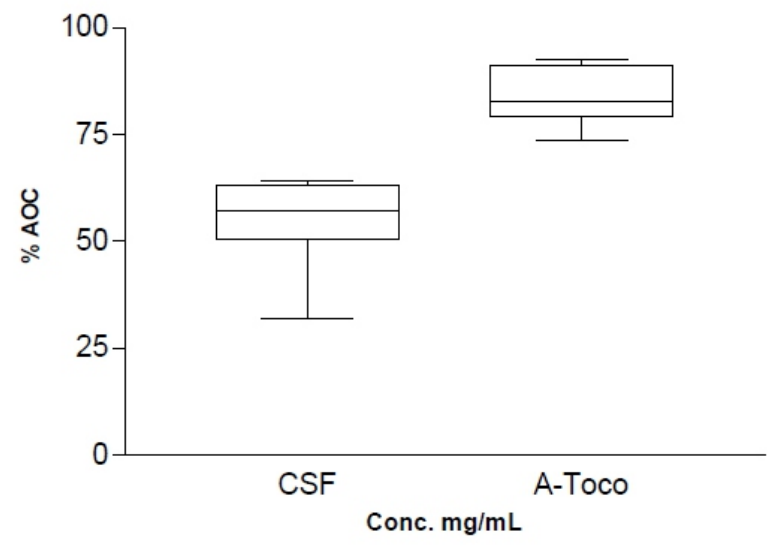

Figure 2: Box-and-whisker plot indicating Antioxidant capacity of $C$. sebestena flower FAMEs (CSF) and $\alpha$-Tocopherol (A-Toco). \%AOC: Percentage Antioxidant capacity; results obtained are mean of duplicate values.

\section{CONCLUSION}

FAMEs have been obtained from C. sebestena flower through a one-step extraction procedure and the chemical composition determined by GC-MS analysis. The one-step extraction procedure seems efficient, time saving, and economical. The GC-MS result indicated seventeen fatty acids including palmitic acid (32.45\%) and myristic acid (21.49\%) as the major fatty acids. The flower is obviously a rich source of palmitic acid. This study suggests that the flower of $C$. sebestena possesses antioxidant activity that might be helpful in preventing or slowing the progress of various oxidative stress related diseases.

\section{REFERENCES}

ADEOSUN, C.B. and A. ADEWUYI, 2012. Identification of the chemical constituents of the petroleum ether extract from the flower of Cordia sebestena. Int'l.Jof Advances in Sci. and Technol. 3: 6 .

ADEOSUN, C.B. and O.S. SOJINU, 2012. The chemical composition of Flower Lipids of Cordia sebestena. Advances in Environmental Biology 6: 2, 655-7. 
ADEOSUN, C.B., S. OLASEINDE, A.O. OPEIFA, and O. ATOLANI, 2013. Essential Oil from the Stem Bark of Cordia sebestena Scavenged Free Radicals. Journal of Acute Medicine 3: 138-141.

AGUNBIADE, F.O, C.B., ADEOSUN, G.G., DARAMOLA, 2013. Nutritional Properties and Potential Values of Cordia sebestena Seed and Seed Oil. GIDA. 38 (3): 127-133.

ATOLANI O, O.S. ADEYEMI, E. AKPAN and C.B. ADEOSUN and G.A. OLATUNJI, 2011. Chemical Composition and Antioxidant Potentials of Kigelia pinnata Root Oil and Extracts. EXCLIJournal. 10:264-273.

ATOLANI O, S. OLADOYE, A.P. OLUYORI and G.A. OLATUNJI, 2012a. New Constituents of Kigelia pinnata Leaves. Singapore Journal of Scientific Research. 2: 47-53.

ATOLANI O, J. OMERE, C.A. OTUECHERE, and A. ADEWUYI, 2012b. Antioxidant and cytotoxicity effects of seed oils from edible fruits. Journal of Acute Disease. 1, 130-134.

BENOIT SC, C.J. Kemp, C.F. ELIAS, W. ABPLANALP, J.P. HERMAN, S. MIGRENNE, A.L. LEFEVRE, C. CRUCIANI-GUGLIELMACCI, C. MAGNAN, F. YU, K. NISWENDER, B.G. IRANI, W.L. HOLLAND, D.J. CLEGG, 2009. Palmitic acid mediates hypothalamic insulin resistance by altering PKC- $\theta$ subcellular localization in rodents. Journal of Clinical Investigation 119 (9): 2577-2587.

BILLER A., M. BOPPRE', L. WITTE, T. HARTMANN, 1994. Pyrrolizidine alkaloids in Chromolaena odorata. Chemical and chemoecological aspects. Phytochemistry 35: 615-619.

DICKEY L.A., B.B. TETER, J. SAMPUGNA and L.C. WOONS, 2002. Comparison of a direct transesterification method and the Bligh and Dyer method to determine fatty acid content in striped bass tissue and diet. North American Journal of Aquaculture, 64:158-163.

DOQAN Y., S. BASLAR, H.H. MERT and A.G. GONG, 2003. Plants used as natural dye sources in Turkey. Economic Botany 57(4): 442-453. 
In vitro Antioxidant Potential of Fatty Acids

DUDEK-Makuch M. and I. MATLAWSKA, 2013. Coumarins in horse chestnut flowers: isolation and quantification by uplc method. Acta Poloniae Pharmaceutica Drug Research. 70 (3): 517-522.

DURUST N., S. OZDEN, E. UMUR, Y. DURUST and M. KUCUKISLAMOGLU, 2001. The Isolation of Carboxylic Acids from the Flowers of Delphinium formosum. TurkJChem. 25: 93-97.

FABIYI OA, O. ATOLANI, O.S. OLUYOMI, G.A. OLATUNJI, 2012. Antioxidant and cytotoxicity of b-amyrin acetate fraction from Bridelia ferruginea leaves. Asian Pacific J Tropical Biomed, 2: S981 - 984.

GARCES R. and M. MANCHA, 1993. One-step lipid extraction and fatty acid methyl esters preparation from fresh plant tissues. Analytical Biochemistry, 211(1): 139-143.

GUDEJ J. and M. TOMCZYK, 1999. Polyphenolic compounds from flowers of Ficaria verna Huds. Acta Pol. Pharm. D Drug Res. 56: 475-476.

HAGELS H., D. WAGENBRETH, and H. SCHILCHER, 1995. Phenolic compounds of buckwheat herb and influence of plant and agricultural factors (Fagopyrum esculentum Moench and Fagopyrum tataricum Gärtner). In T. Matano and A. Ujihara, eds., Current Advances in Buckwheat Research: Proceedings of the 6th International Symposium on Buckwheat, pp.801-809, Shinshu University Press, Shinshu, China.

HARTMANN T. and M. ZIMMER, 1986. Organ-specific distribution and accumulation of pyrrolizidine alkaloids during the life history of two annual Senecio species. J. Plant Physiol., 122: 67-80.

ILIĆ S.B., S.S. KONSTANTINOVIĆ and Z.B. TODOROVIĆ Z, 2004. Flavonoids from flower of linum capitatum kit. Physics, Chemistry and Technology, $3,1,67-71$.

INDARTI E. M.I.A., MAJID, R. HASHIM, and A. CHONG, 2005, Direct FAME synthesis for rapid total lipid analysis from fish oil and cod liver oil. Journal of Food Composition and Analysis, 18: 161-170.

LEPAGE G and C.C. ROY, 1986. Direct transesterification of all classes of lipids in a one-step reaction, Journal of Lipid Research, 27: 114-120 
MARTINO E., I. RAMAIOLA, M. URBANO, F. BRACCO, F., S. COLLINA, 2006. Microwave-assisted extraction of coumarin and related compounds from Melilotus officinalis (L.) Pallas as an alternative to Soxhlet and ultrasound-assisted extraction.J. Chromatogr A.1125: 147-151.

MEIER S., S.A. MJOS, H. JOENSEN and O. GRAHL-NIELSEN, 2006. Validation of a one-step extraction/methylation method for determination of fatty acids and cholesterol in marine tissues, Journal of Chromatography A, 1104: 291-298.

OYUGI D.A, F.O. AYORINDE, A. GUGSSA, A. ALLEN, E.B. IZEVBIGIE, B. ERIBO and W.A. ANDERSON, 2011. Biological activity and mass spectrometric analysis of Vernonia amygdalina fractions. J. Biosci. Tech. 2(3): 287-304.

PARK E.J., Y. KIM and J. KIM, 2000. Acylated Flavonol Glycosides from the Flower of Inula Britannica. J. Nat. Prod., 63: 34-36.

PEREIRA A.M.S. 1997. Propagação e co-cultivo de células como fatores predisponentes à produção de cumarina em Mikania glomerata Sprengel (guaco). Botucatu: UNESP. Tese (Doutorado em Agricultura). p 82

SHEARD C., H.D. CAYLOR and C. SCHLOTTHAUER, 1928. Photosensitization of Animals after the Ingestion of Buckwheat.JEM 47 (6): 1013-1028.

TOMCZYK M and J. GUDEJ 2002a, Quercetin and kaempferol glycosides from Ficaria verna flowers and their structure studied by 2D NMR spectroscopy. Polish J. Chem. 76: 1601-1605.

TOMCZYK M and J. GUDEJ 2002b, Composition of lipophylic extracts from Ficaria verna Huds. flowers. Rocz. Akad. Med. Białymst. 47: 213-217.

XIAO L. 2010. Evaluation of Extraction Methods for Recovery of Fatty Acids from Marine Products. Master Thesis of EMQAL Project. University of Bergen. Norway. Pp.4-17. 